\title{
Reconsolidation of a Cocaine-Associated Stimulus Requires Amygdalar Protein Kinase A
}

\author{
Hayde Sanchez, ${ }^{\star}$ Jennifer J. Quinn, ${ }^{\star}$ Mary M. Torregrossa, ${ }^{\star}$ and Jane R. Taylor \\ Department of Psychiatry, Division of Molecular Psychiatry, Yale University School of Medicine, New Haven, Connecticut 06508
}

Drug addiction is a chronic disorder associated with recurrent craving and relapse often precipitated by the presence of drug-associated stimuli. Pharmacological and behavioral treatments that disrupt drug-associated stimulus memories could be beneficial in the treatment of addictive disorders. Memory restabilization (or reconsolidation) following retrieval of drug-paired stimuli depends upon the amygdala. Here we assessed whether amygdalar PKA is required for the reconsolidation of an appetitive, cocaine-paired stimulus. Rats were trained to lever press for intravenous cocaine infusions paired with a light/tone conditioned stimulus. After $12 \mathrm{~d}$ of acquisition, rats either underwent lever extinction $(8-12 \mathrm{~d})$ followed by light/tone reactivation and subsequent cue-induced and cocaine-induced (15 mg/kg, i.p.) reinstatement testing or were subsequently tested to assess the ability of the light/tone stimulus to serve as a conditioned reinforcer in the acquisition of a new instrumental response (nose poking). Bilateral intra-amygdalar infusions of the PKA inhibitor Rp-cAMPS (18 $\mu \mathrm{g}$ per side) given immediately following light/tone stimulus reactivation decreased subsequent cue-induced reinstatement and responding with a conditioned reinforcer, while having no effect on cocaine-induced reinstatement. Intra-amygdalar infusions of Rp-cAMPS made $3 \mathrm{~h}$ following reactivation or immediately following no stimulus reactivation had no effect on subsequent cue-induced reinstatement. These data show that memory reconsolidation for a cocainepaired stimulus is retrieval dependent and time limited and critically depends upon amygdalar PKA.

\section{Introduction}

Stimulus-elicited craving often accompanies compulsive drug use and presents a major challenge to sustained abstinence. Drugassociated stimuli acquire powerful conditioned reinforcing properties, having a seemingly indelible influence on drugoriented behavior. The amygdala plays a central role in associative learning whereby appetitive or aversive events become associated with an initially neutral stimulus (Jentsch and Taylor, 1999; Feltenstein and See, 2008; Robbins et al., 2008). Disruptions of the basolateral amygdala (BLA) impair the ability of these stimuli to acquire or maintain reinforcing properties following pairings with food, sex, or drugs (Cador et al., 1989; Everitt et al., 1989; Lee et al., 2005) and disrupt stimulus-induced reinstatement to cocaine seeking (e.g., Grimm and See, 2000; Kantak et al., 2002; Fuchs et al., 2006; Feltenstein and See, 2007). In abstinent cocaine users, these stimuli elicit simultaneous drug craving and robust amygdalar activation (Bonson et al., 2002; Volkow et al., 2008).

Attempts to reduce the profound influences of these conditioned stimuli (CSs) by exposure therapy/extinction procedures alone have been unsuccessful (e.g., Weiss et al., 2001; Crombag

Received July 2, 2009; revised Jan. 26, 2010; accepted Feb. 5, 2010.

This work was supported by National Institutes of Health Grants DA015222 and DA008227 (J.R.T.) and F32 DA022812 (M.M.T.), and the Connecticut Mental Health Center.

*H.S., J.J.Q., and M.M.T. contributed equally to this work.

Correspondence should be addressed to Dr. Jane R. Taylor, Department of Psychiatry, Division of Molecular Psychiatry, Yale University School of Medicine, Connecticut Mental Health Center, S307, 34 Park Street, New Haven, CT 06508. E-mail: jane.taylor@yale.edu.

J. J. Quinn's present address: Department of Psychology, Miami University, 90 North Patterson Avenue, Oxford, $\mathrm{OH} 45056$.

DOI:10.1523/JNEUROSCI.3149-09.2010

Copyright $\odot 2010$ the authors $\quad 0270-6474 / 10 / 304401-07 \$ 15.00 / 0$ and Shaham, 2002; Conklin and Tiffany, 2002; Taylor et al., 2009). However, manipulations targeting the process of memory restabilization following retrieval ("reconsolidation") may be more efficacious in the treatment of drug addiction since their effects are generally more enduring and context independent (Tronson and Taylor, 2007; Taylor et al., 2009). Systemic and intra-amygdalar pharmacological manipulations during, or shortly following, retrieval of a drug CS memory alter subsequent performance with that CS. For instance, systemic administration of the NMDA receptor antagonist MK-801 disrupts the reconsolidation of cocaine conditioned place preference memories (Kelley et al., 2007; Brown et al., 2008). More specifically, BLA knockdown of the immediate early gene zif268 before reactivation of a cocaine-associated stimulus reduces the ability of that CS to serve as a conditioned reinforcer (CR) in the acquisition of a new instrumental response (Lee et al., 2005) or to later reinstate cocaine seeking following extinction (Lee et al., 2006). Further, intra-BLA antagonism of NMDA receptors immediately before reactivation of a cocaine $\mathrm{CS}$ disrupted subsequent $\mathrm{CR}$ responding for that CS (Milton et al., 2008), whereas the partial NMDA agonist D-cycloserine had opposite effects (Lee et al., 2009).

cAMP-dependent protein kinase A (PKA) activity and its downstream targets are critical for some forms of amygdalar synaptic plasticity (Huang and Kandel, 1998; Rammes et al., 2000). Further, acquisition and consolidation of fear conditioning are disrupted by intra-BLA inhibition of PKA (Goosens et al., 2000; Schafe and LeDoux, 2000). Importantly, our laboratory has demonstrated a role for amygdalar PKA in the reconsolidation of auditory fear memories (Tronson et al., 2006). For instance, postretrieval inhibition of PKA in the BLA by infusions of Rpadenosine $3^{\prime}, 5^{\prime}$-cyclic monophosphorothioate hydrate triethyl- 
ammonium salt (Rp-cAMPS) attenuates subsequent freezing to the auditory stimulus. To date, no studies have addressed a role for PKA within the BLA in appetitive memory reconsolidation. The present experiments used postretrieval BLA manipulations to examine reconsolidation of CS-cocaine memories assessed by reinstatement of cocaine seeking and the CS's ability to subsequently serve as a CR.

\section{Materials and Methods}

Subjects. Fifty-three male Sprague Dawley rats (280-320 g of weight; experiment $1 N=16$; experiment $2 N=12$; experiment $3 N=10$; experiment $4 N=15$ ) were purchased from Charles River Laboratories. Upon arrival, rats were housed in pairs, given ad libitum access to food and water, and allowed to acclimate for at least $7 \mathrm{~d}$ before the start of the experiment. The animal room was temperature and humidity controlled and maintained on a 12/12 h light/dark cycle. All experiments were conducted during the dark phase of the rat cycle. All procedures were conducted in accordance with the policies of the Yale University Institutional Animal Care and Use Committee and conformed to National Institutes of Health Guidelines on the Care and Use of Laboratory Animals.

Surgery. Rats were anesthetized with $55 \mathrm{mg} / \mathrm{kg}$ sodium pentobarbital (i.p.) followed by $0.4 \mathrm{mg} / \mathrm{kg}$ atropine sulfate (i.p.) and $5 \mathrm{ml}$ of saline (s.c.). Rats were implanted with a chronic indwelling catheter (Camcaths) into the right jugular vein and bilateral guide cannulae (22 gauge; Plastics One) targeting the BLA (AP $-3.0 \mathrm{~mm}, \mathrm{ML} \pm 5.3 \mathrm{~mm}, \mathrm{DV}-7.9 \mathrm{~mm}$ relative to bregma). The intravenous catheter was kept patent by an infusion of a $0.1 \mathrm{ml}$ of heparinized saline (30 USP heparin/saline; Hospira) every $2 \mathrm{~d}$. The intracranial cannulae were kept patent by the insertion of obturators that were replaced daily. After surgery, rats were housed individually with ad libitum access to food and water. Rats were allowed to recover for a week before the start of the training. Rats were weighed twice before training and daily once behavioral training commenced.

Behavioral procedures. Rats were trained in sound-attenuated operant conditioning chambers (Med Associates). The operant box was equipped with two retractable levers (positioned next to one another on the right wall of the operant chamber), a stimulus light, a tone generator, and a fan that provided background noise $(65 \mathrm{~dB})$. Rats were food restricted to $90 \%$ of their free-feeding body weight and maintained at that weight for the duration of the experiment. Rats underwent cocaine selfadministration for $10-12 \mathrm{~d}$ in daily $1 \mathrm{~h}$ sessions under a fixed-ratio one (FR1) schedule of reinforcement on the active lever. Inactive lever responses were recorded but did not result in the presentation of any stimuli or infusions. Each infusion of cocaine $(0.5 \mathrm{mg} / \mathrm{kg})$ was paired with a $10 \mathrm{~s}$ light/tone ( $75-78 \mathrm{~dB})$ CS. Rats had a $10 \mathrm{~s}$ timeout between infusions. Rats were removed from the chambers upon termination of the session. In the experiments involving cue-induced reinstatement, lever pressing was extinguished for $8-12 \mathrm{~d}$ before reinstatement testing. During the $1 \mathrm{~h}$ daily extinction sessions, both levers were available but responses on either lever had no programmed consequences.

Following the last extinction day (reinstatement experiments; experiments $1-3$ ) or $12 \mathrm{~d}$ after the last acquisition day of cocaine selfadministration (conditioned reinforcement experiment; experiment 4), rats underwent stimulus reactivation. Only rats that fulfilled the criteria for acquisition ( $\geq 10$ infusions for each of the last 3 consecutive selfadministration sessions) and extinction ( $<25$ active lever responses) were reactivated. The reactivation session took place in a novel context (different lighting, solid floor, novel odor): three presentations of the $10 \mathrm{~s}$ light/tone stimulus were delivered with an interstimulus interval of 1 min. Immediately following the reactivation session (experiments 1 and 4), rats underwent a bilateral infusion into the BLA (see below, Drug infusions) (see Figs. 1a, 4a). Delayed-reactivation controls received infusions $3 \mathrm{~h}$ after the reactivation session (experiment 2) (see Fig. 2a). Nonreactivated controls were placed into the novel reactivation context but did not receive presentations of the light/tone stimuli and then received infusions immediately following removal from the context (experiment 3) (see Fig. 3a). Rats were returned to their home cages in the animal colony following the infusion procedure.
Twenty-four hours after the reactivation/infusion, rats were tested in cue-induced reinstatement (experiments 1-3) or conditioned reinforcement (experiment 4). For cue-induced reinstatement, rats were returned to the self-administration context and responding on both levers was recorded for $1 \mathrm{~h}$. Active lever responding resulted in presentation of the light/tone CS but no cocaine infusion. Inactive lever responding had no programmed consequences. For 2 consecutive days following this test, the rats underwent another $2 \mathrm{~d}$ of lever extinction before undergoing a cocaine-induced reinstatement test. For this test, rats were injected with cocaine $(15 \mathrm{mg} / \mathrm{kg}$, i.p.) and placed into the self-administration context. Both active lever and inactive lever responding were recorded, but neither yielded any presentations of stimuli or infusions. This single-dose cocaine-induced reinstatement test was conducted to provide some evidence for the specificity of the Rp-cAMPS manipulation to the cue reactivation, as opposed to a general decrease in responding.

CR testing (experiment 4 ) (see Fig. 4a) was used to assess the ability of the light/tone stimulus to serve as a reinforcer for the acquisition of a new instrumental response (nose poking). CR testing (30 min session) took place in a third (novel) context equipped with two nose-poke apertures along a curved wall on the left side of the chamber. One of the nose pokes was designated the active nose poke, and the other was the inactive nose poke. Active nose-poke responses resulted in presentation of the light/ tone stimulus for $1 \mathrm{~s}$. Inactive nose-poke responses had no programmed consequences.

Drug infusions. Infusions were performed using a syringe pump with $10 \mu$ l Hamilton syringes connected to injection cannulae (28 gauge; Plastics One) via polyethylene tubing. Rats received a bilateral infusion of the PKA inhibitor Rp-cAMPS (18 $\mu \mathrm{g}$ per side, $0.5 \mu \mathrm{l} / \mathrm{min}$, for $2 \mathrm{~min}$; SigmaAldrich) into the BLA (Jentsch et al., 2002; Tronson et al., 2006) while controls received an equal volume infusion of vehicle $(1 \times \mathrm{PBS})$. Injectors remained in place for $2 \mathrm{~min}$ following the infusion to allow for diffusion of the solution.

Histological assessment. At the end of each experiment, rats were anesthetized $(90 \mathrm{mg} / \mathrm{kg}$ sodium pentobarbital, i.p.) and infused with thionin ( $1 \%$; Sigma-Aldrich) into the BLA at the same volume and rate used for experimental drug infusion to subsequently visualize the location of the injector tip. The injectors remained in place for $2 \mathrm{~min}$ following the infusion. Animals were transcardially perfused with $0.9 \%$ saline followed by $10 \%$ formalin. Brains were stored in $10 \%$ formalin until $2 \mathrm{~d}$ before slicing, at which point they were transferred to $10 \%$ formalin/30\% sucrose. The brains were sliced in $50 \mu \mathrm{m}$ coronal sections using a cryostat at approximately $-16^{\circ} \mathrm{C}$. Every fourth slice of the amygdala was mounted on a microscope slide, dried, and stained using $0.5 \%$ cresyl violet (SigmaAldrich). Verification of infusion location was made by an observer who was blind to the experimental condition and behavioral performance of the animal.

Statistical analysis. Acquisition of cocaine self-administration was analyzed using repeated-measures ANOVAs (rm-ANOVAs) across days for the following measures: number of infusions, total number of active lever responses, and total number of inactive lever responses. Extinction of lever pressing was analyzed using rm-ANOVAs across days for the following measures: total number of active lever responses and total number of inactive lever responses. Across all acquisition and extinction analyses, the groups were split into the to-be-infused conditions to assess any potential group differences before drug treatment. Cue- and druginduced reinstatement tests were analyzed using rm-ANOVAs across the last extinction day and the reinstatement test for the following measures: total number of active lever responses and total number of inactive lever responses. Conditioned reinforcement was analyzed using rm-ANOVAs across the active and inactive nose-poke responses during the test. All significant rm-ANOVAs were followed with pairwise comparisons using Fisher's PLSD $(p<0.05)$.

\section{Results}

Experiment 1: immediate post-reactivation intra-amygdalar PKA inhibition reduces subsequent cue-induced reinstatement

All of the cannula placements were within or adjacent to the boundaries of the BLA (Fig. 1b). Acquisition of cocaine self- 
a
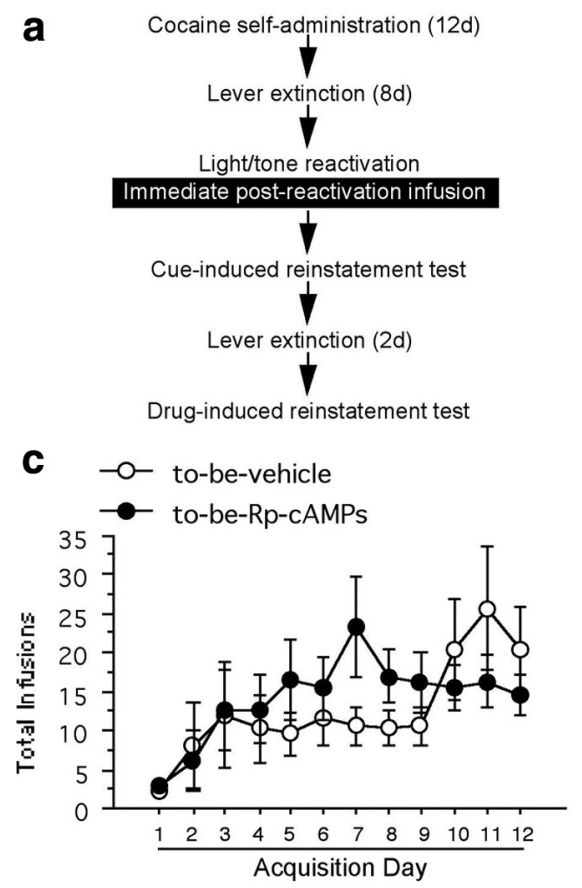

e

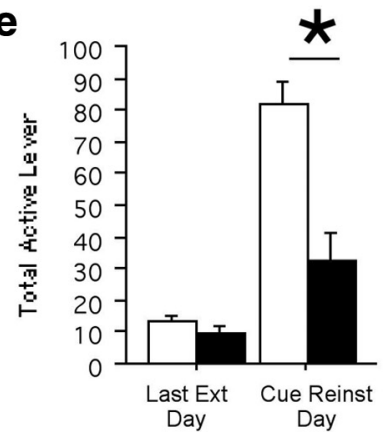

b

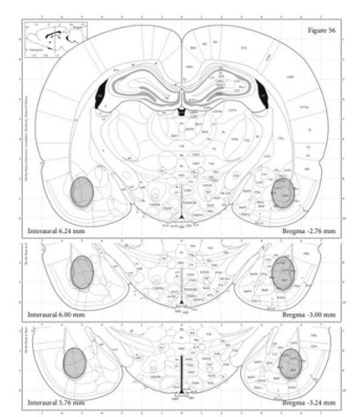

d

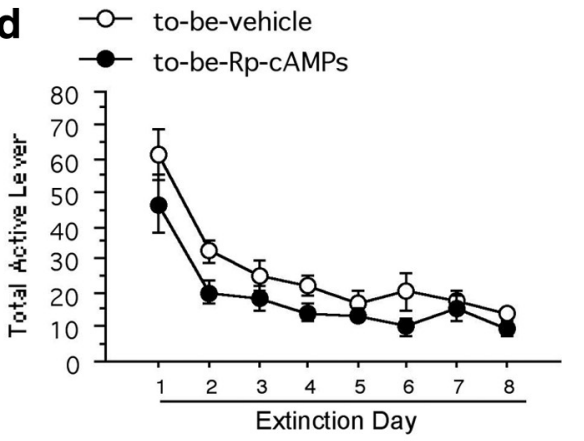

f

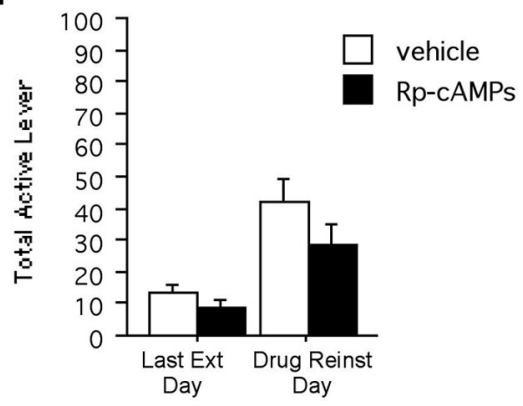

Figure 1. $\quad \boldsymbol{a}$, Schematic representation of the experimental procedure. $\boldsymbol{b}$, Diagram of the region in which all infusions were located across all experiments [atlas figures from Paxinos and Watson (2005)]. c, Total number of infusions across acquisition of cocaine self-administration. $\boldsymbol{d}$, Total number of active lever responses across lever extinction. $\boldsymbol{e}$, Active lever responses during the last day of extinction and the cue-induced reinstatement test. $\boldsymbol{f}$, Active lever responses during the last day of extinction and the cocaine-induced reinstatement test.

administration did not differ between the rats that would be infused with Rp-cAMPS $(N=9)$ versus vehicle $(N=7)$ immediately following reactivation; there were no differences in the number of cocaine infusions (Fig. 1c), active lever responses, or inactive lever responses ( $p$ values $>0.05$ ). There was no significant difference between the groups across the $8 \mathrm{~d}$ of lever press extinction according to their active or inactive lever responses $(p$ values $>0.05$ ) (Fig. 1d). There was a significant interaction between active lever presses during the last day of extinction and cue-induced reinstatement among the Rp-cAMPS- and vehicle-infused animals $\left(F_{(1,14)}=14.37, p<0.01\right)$ (Fig. 1e). RpcAMPS following reactivation resulted in a subsequent decrease in cue-induced reinstatement of active lever responses compared to vehicle controls (Fisher's PLSD $p<0.05$ ), while there was no difference between the groups on the last day of extinction. There was no interaction between inactive lever presses during the last day of extinction and cue-induced reinstatement among the Rp-cAMPS- and vehicle-infused animals $(p>0.05)$. Importantly, there was no significant interaction between active lever presses during the last day of extinction and cocaine-induced reinstatement among the Rp-cAMPSand vehicle-infused animals $(p>0.05)$ (Fig. 1f). Similarly, there was no significant interaction between inactive lever presses during the last day of extinction and cocaine-induced reinstatement among the Rp-cAMPS- and vehicleinfused animals $(p>0.05)$. Therefore, the disruptive effect of Rp-cAMPS seen above is specific to the cocaine-associated light/tone stimulus-induced reinstatement and does not alter cocaine-induced reinstatement.

\section{Experiment 2: intra-amygdalar PKA inhibition $3 \mathrm{~h}$ following reactivation has no effect on subsequent cue-induced reinstatement}

All of the cannula placements were within or adjacent to the boundaries of the BLA. Acquisition of cocaine self-administration did not differ between the rats that would be infused with Rp-cAMPS $(N=6)$ versus vehicle $(N=6) 3 \mathrm{~h}$ following reactivation; there were no differences in the number of cocaine infusions (Fig. $2 b$ ), active lever responses, or inactive lever responses ( $p$ values $>0.05$ ). There was a significant interaction between the groups across the $12 \mathrm{~d}$ of lever press extinction in active lever responses $\left(F_{(11,110)}=3.25, p<0.05\right)$. However, there were no differences between the groups across the last $3 \mathrm{~d}$ of extinction ( $p>0.05)$ (Fig. $2 c$ ). Likewise, there were no differences between groups in inactive lever responses across all $12 \mathrm{~d}$ of extinction or across the last 3 extinction days ( $p$ values $>0.05$ ). There was also no significant interaction between active lever presses during the last day of extinction and cue-induced reinstatement among the Rp-cAMPS- and vehicleinfused delayed-reactivation animals $(p>$ 0.05) (Fig. 2d). Likewise, there was no significant interaction between inactive lever presses during the last day of extinction and cue-induced reinstatement among the Rp-cAMPS- and vehicleinfused delayed-reactivation animals $(p>0.05)$. Therefore, the effect of Rp-cAMPS seen in experiment 1 is temporally specific, requiring that inhibition of PKA occur within $<3$ h of the light/ tone stimulus reactivation.

\section{Experiment 3: immediate post-reactivation intra-amygdalar PKA inhibition has no effect on subsequent cue-induced reinstatement in non-reactivated controls}

All of the cannula placements were within or adjacent to the boundaries of the BLA. Acquisition of cocaine self-administration differed somewhat between the rats that would not undergo light/ tone stimulus reactivation but would be infused with Rp-cAMPS $(N=5)$ versus vehicle $(N=5)$ (Fig. $3 b)$. There was a difference between Rp-cAMPS and vehicle rats across acquisition days in the number of cocaine infusions $\left(F_{(11,88)}=2.34, p<0.05\right)$. However, there was no difference between the groups in the total number of infusions taken throughout acquisition $(p>0.05)$. 
Likewise, there was a difference between Rp-cAMPS and vehicle rats across acquisition days in the number of active lever responses $\left(F_{(11,88)}=2.31, p<0.05\right)$. However, there was no difference between the groups in the total number of active lever responses made throughout acquisition $(p>0.05)$. There were no differences in the number of inactive lever responses across acquisition $(p>0.05)$. In this experiment, there were no differences between the groups across any of the $8 \mathrm{~d}$ of lever press extinction according to their active lever responses (Fig. $3 c$ ) and inactive lever responses ( $p$ values $>0.05$ ). There was no significant interaction between active lever presses during the last day of extinction and cue-induced reinstatement among the Rp-cAMPS- and vehicle-infused non-reactivated animals $\left(F_{(1,8)}=1.10, p>0.05\right)$ (Fig. $\left.3 d\right)$. There was an unexpected interaction between inactive lever presses during the last day of extinction and cue-induced reinstatement among the Rp-cAMPS- and vehicle-infused non-reactivated animals $\left(F_{(1,8)}=8.98, p<\right.$ 0.05). In summary, the effect of Rp-cAMPS seen in experiment 1 depends upon the light/tone stimulus having been reactivated.

Experiment 4: immediate post-reactivation intra-amygdalar PKA inhibition reduces subsequent conditioned reinforcement of a novel instrumental response

All of the cannula placements were within or adjacent to the boundaries of the BLA. Acquisition of cocaine self-administration did not differ between the rats that would be infused with Rp-cAMPS $(N=8)$ versus vehicle $(N=7)$ following reactivation; there were no differences in the number of cocaine infusions (Fig. $4 b$ ), active lever responses, or inactive lever responses ( $p$ values $>0.05$ ). These rats did not undergo lever press extinction before conditioned reinforcement testing. They underwent conditioned reinforcement testing to assess whether the light/tone stimulus was capable of serving as a conditioned reinforcer for the acquisition of a novel instrumental response (nose poking). There was no significant interaction between active and inactive nose pokes during the conditioned reinforcement test $\left(F_{(1,13)}=1.18\right.$, $p>0.05$ ) (Fig. 4c). However, pairwise comparisons using Fisher's PLSD between Rp-cAMPS- and vehicle-infused rats showed a significant decrement in active $(p<0.05)$, but not inactive, nose pokes. Thus, intra-amygdalar Rp-cAMPS following reactivation diminishes the light/tone stimulus's ability to serve as a conditioned reinforcer. This accords well with the results of experiment 1, where similar infusions diminished the light/tone stimulus's ability to reinstate cocaine seeking. a
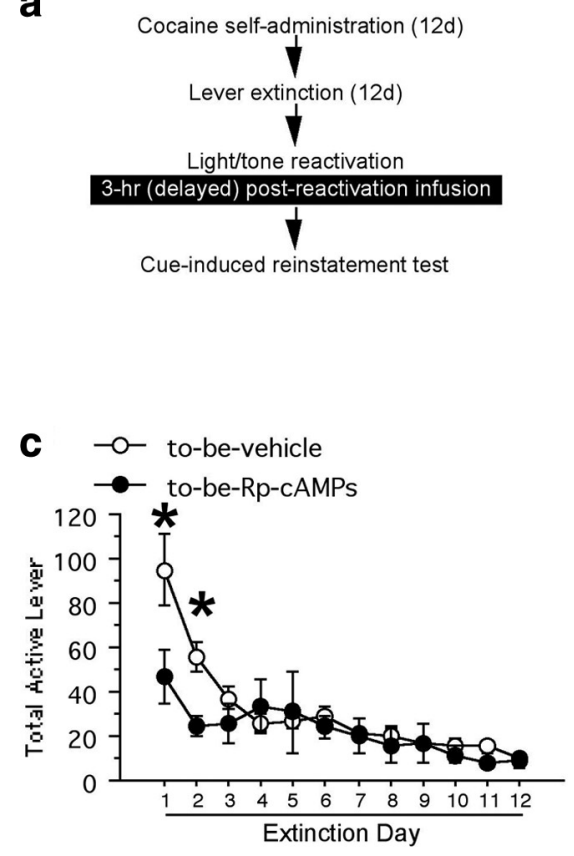

Figure 2. $\boldsymbol{a}$, Schematic representation of the experimental procedure. $\boldsymbol{b}$, Total number of infusions across acquisition of cocaine self-administration. $\boldsymbol{c}$, Total number of active lever responses across lever extinction. $\boldsymbol{d}$, Active lever responses during the last day of extinction and the cue-induced reinstatement test.

a

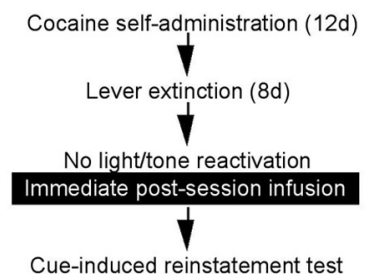

C

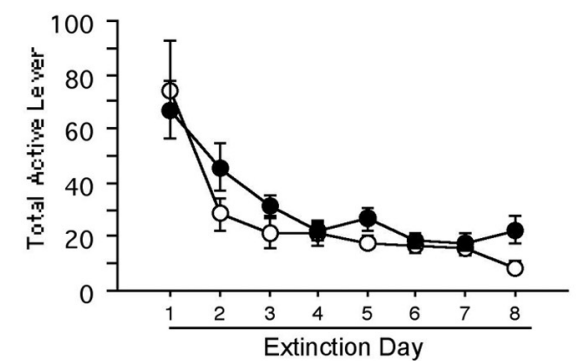

b $\quad \stackrel{-}{\longrightarrow} \rightarrow$ to-be-vehicle

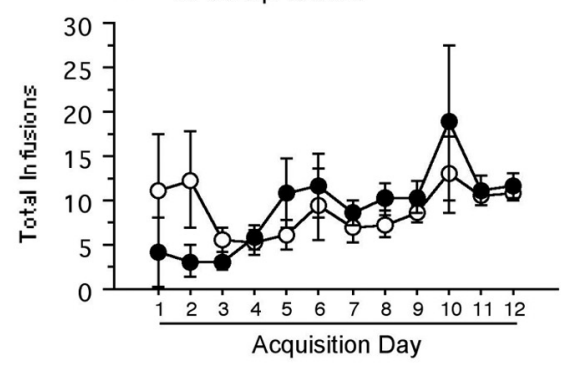

d

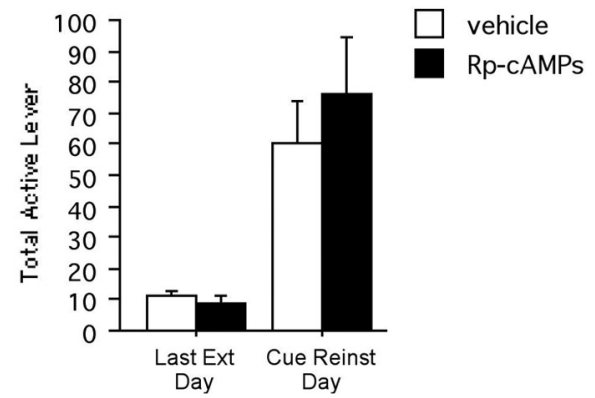

Figure 3. $\quad \boldsymbol{a}$, Schematic representation of the experimental procedure. $\boldsymbol{b}$, Total number of infusions across acquisition of cocaine self-administration. $\boldsymbol{c}$, Total number of active lever responses across lever extinction. $\boldsymbol{d}$, Active lever responses during the last day of extinction and the cue-induced reinstatement test.

\section{Discussion}

The present results demonstrate that intra-BLA infusion of the PKA inhibitor Rp-cAMPS following reactivation of a stimulus that had been paired previously with self-administered cocaine disrupts the ability of that stimulus to later reinstate cocaine seeking or to serve as a conditioned reinforcer for the acquisition of a 
a

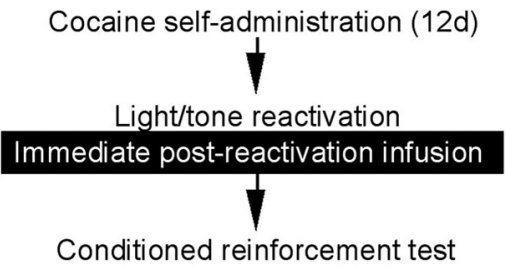

b
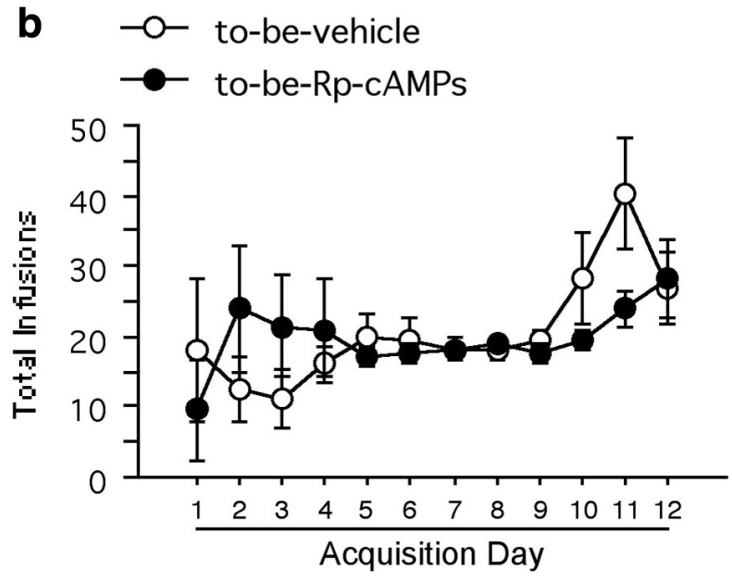

C

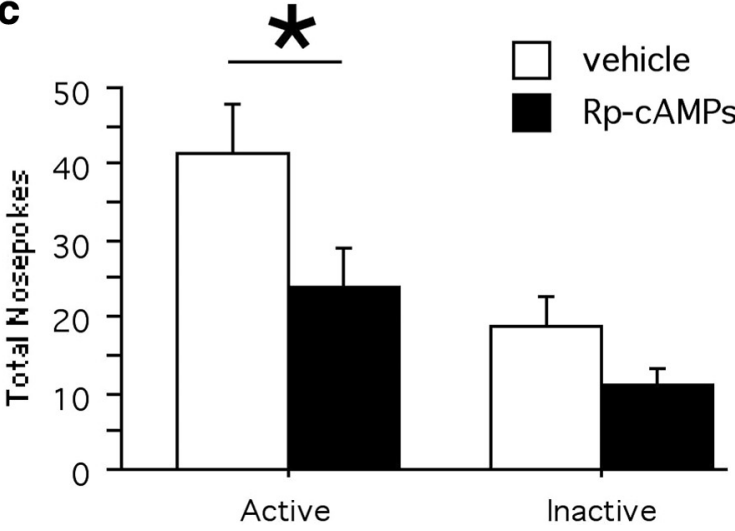

Figure 4. $\boldsymbol{a}$, Schematic representation of the experimental procedure. $\boldsymbol{b}$, Total number of infusions across acquisition of cocaine self-administration. $c$, Active and inactive nose-poke responses during the conditioned reinforcement test (acquisition of a new instrumental nosepoking response).

new instrumental response. Here, we used post-reactivation rather than pre-reactivation manipulations that arguably target the reconsolidation processes specifically (as opposed to new learning/extinction; see Taylor et al., 2009). In addition, three essential control analyses were conducted. First, postreactivation BLA infusions of Rp-cAMPS did not disrupt drug-induced reinstatement of cocaine seeking as it did CSinduced reinstatement, showing that our drug manipulation is specific to mnemonic processing of the cocaine-paired CS. However, it should be noted that only a single systemic cocaine dose was used for drug-induced reinstatement; to entirely eliminate a potential effect of post-reactivation Rp-cAMPS on subsequent drug-induced reinstatement, a more thorough analysis using a range of systemic cocaine doses would be required. The present single-dose data provide some evidence for the specificity of the Rp-cAMPS manipulation to the cue reactivation, as opposed to a general decrease in responding. Second, these infusions had no effect on subsequent stimulus-induced reinstatement in rats that did not undergo stimulus reactivation, ensuring that Rp-cAMPS had its above effects on a process initiated by retrieval, as opposed to a long-lasting consolidation process (Dudai and Eisenberg, 2004). Finally, intra-BLA infusions of Rp-cAMPS $3 \mathrm{~h}$ following stimulus reactivation had no effect on the stimulus's ability to subsequently reinstate cocaine seeking, demonstrating a critical postretrieval time window during which Rp-cAMPS is capable of altering memory reconsolidation of the reactivated stimulus. Together, these data conclusively show that PKA modulates memory reconsolidation for a cocaine-associated stimulus in a retrievaldependent and time-limited manner.

These data are entirely consistent with the role for amygdalar PKA modulation in memory reconsolidation of auditory fear CSs (Tronson et al., 2007), indicating that a conserved mnemonic process governing both appetitive and aversive stimulus memories is possible (see also Hellemans et al., 2006). PKA exerts its effects on memory consolidation and synaptic plasticity via multiple cellular processes including the activation of transcription factors such as cAMP response element-binding protein (CREB) (e.g., Huang et al., 2000) and Zif268 (also known as EGR1, NGFI-A, and Krox24) (Bozon et al., 2002; Tronson and Taylor, 2007) that regulate the transcription of genes encoding proteins required for the formation of long-term memories. Consistent with a role for these downstream transcription factors in memory consolidation, reduced activations of CREB and Zif268 correlate with disruptions in reconsolidation of a cocaine conditioned place preference (Miller and Marshall, 2005) and win-stay radial arm maze task (Roullet and Sara, 1998). Importantly, Lee et al. $(2005,2006)$ have shown in an elegant series of studies that knockdown of Zif268 in the BLA using an antisense oligonucleotide profoundly disrupts memory reconsolidation for drugassociated stimuli and, thereby, eliminates the ability of those stimuli to reinstate drug seeking (Lee et al., 2006), maintain responding under a second-order schedule of reinforcement (Lee et al., 2006), or serve as a conditioned reinforcer (Lee et al., 2005). Further, they have recently shown a similar effect on conditioned reinforcement following intra-BLA NMDA receptor antagonism at the time of stimulus reactivation that also yielded a downregulation in Zif268 expression (Milton et al., 2008).

The designs of our studies extend previous reports by assessing the role for context-specificity in reconsolidation of CS-cocaine memories. As mentioned previously, attempts to reduce the profound influences of drug CSs by exposure therapy/extinction procedures alone typically result in a return of the extinguished stimulus memory upon a change in the physical or temporal context (e.g., Weiss et al., 2001; Crombag and Shaham, 2002; Conklin and Tiffany, 2002; Taylor et al., 2009). In order for pharmacological treatments targeting memory reconsolidation to have more success, it would be important to demonstrate that such manipulations can be context independent. Previous studies of memory reconsolidation with cocaine-associated stimuli have maintained a consistent context throughout all phases of analysis: cocaine self-administration acquisition, stimulus reactivation, and conditioned reinforcement/cue-induced reinstatement testing (Lee et al., 2005, 2006; Milton et al., 2008). In the present experiments, stimulus reactivation always occurred in a novel context that was distinct (geometry, tactile, odor, lighting) from the cocaine self-administration acquisition context. While cue-induced reinstatement testing occurred in the original selfadministration context, conditioned reinforcement testing was conducted in a third (novel) context. In both tests, there was a disruption in stimulus-reinforced responding in rats that received post-reactivation BLA Rp-cAMPS. Thus, the present re- 
sults demonstrate a role for BLA PKA in the context-independent memory reconsolidation of a cocaine CS and suggest the utility of this treatment strategy.

There is still considerable controversy regarding the process(es) underlying the reconsolidation phenomenon (Dudai, 2006; Miller and Matzel, 2006; Tronson and Taylor, 2007; Lee, 2008). While some argue that manipulations at the time of memory reactivation alter the re-storage of that memory during a transient retrieval-induced labile period (Squire, 2006; Alberini, 2008; Nader and Hardt, 2009), others argue that such manipulations make the memory less retrievable without altering the stored memory (Cahill et al., 2001; Power et al., 2006; Riccio et al., 2006). The most significant data regarding this controversy are those showing only transient amnesia following manipulations during, or shortly following, retrieval (e.g., Mactutus et al., 1979; Lattal and Abel, 2004); that is, the disruption in memory fades either spontaneously with time (Lattal and Abel, 2004; Amaral et al., 2007) or with the presentation of reminder stimuli (Eisenberg and Dudai, 2004). Generally, demonstrations of transient amnesia are interpreted as retrieval failures, whereas enduring amnesias are often interpreted as storage deficits. While we did not assess the duration of memory alterations for the cocaineassociated stimuli in the present experiments, other studies have shown enduring (up to $50 \mathrm{~d}$ ) memory impairments with BLA manipulations administered at the time of reactivation (Lee et al., 2005, 2006; Milton et al., 2008). This would suggest that restorage underlies the reconsolidation of cocaine-associated stimuli in the BLA. However, Amaral et al. (2008) have recently proposed a model to parsimoniously account for both transient and enduring amnesias without assuming distinct underlying retrieval and storage mechanisms.

Regardless of the interpretation (retrieval vs storage), demonstrations of pharmacological manipulations of long-term memories during a retrieval-induced labile period suggest an especially efficacious avenue for therapies targeting the elimination of highly intrusive memories that often result in debilitating psychiatric conditions such as drug-craving and relapse in addiction as well as traumatic flashbacks in posttraumatic stress disorder (McCleery and Harvey, 2004; Debiec and LeDoux, 2006; Tronson and Taylor, 2007). The long-lasting, context-independent nature of these reconsolidation-targeted manipulations may make them superior to the currently more exploited exposure/extinction-based behavioral approaches typically used in therapeutic settings (O'Brien et al., 1990; Conklin and Tiffany, 2002; Taylor et al., 2009). This strategy will likely provide an enduring reduction in the motivational impact of drug-associated stimuli that powerfully elicit drugrelated behavior-promoting abstinence by allowing for robust and persistent suppression of drug relapse-and the development of systemic PKA antagonism-based pharmacotherapies may be especially useful in this regard.

\section{References}

Alberini CM (2008) The role of protein synthesis during the labile phases of memory: revisiting the skepticism. Neurobiol Learn Mem 89:234-246.

Amaral OB, Luft T, Cammarota M, Izquierdo I, Roesler R (2007) Temporary inactivation of the dorsal hippocampus induces a transient impairment in retrieval of aversive memory. Behav Brain Res 180:113-118.

Amaral OB, Osan R, Roesler R, Tort AB (2008) A synaptic reinforcementbased model for transient amnesia following disruptions of memory consolidation and reconsolidation. Hippocampus 18:584-601.

Bonson KR, Grant SJ, Contoreggi CS, Links JM, Metcalfe J, Weyl HL, Kurian V, Ernst M, London ED (2002) Neural systems and cue-induced cocaine craving. Neuropsychopharmacology 26:376-386.
Bozon B, Davis S, Laroche S (2002) Regulated transcription of the immediateearly gene Zif268: mechanisms and gene dosage-dependent function in synaptic plasticity and memory formation. Hippocampus 12:570-577.

Brown TE, Lee BR, Sorg BA (2008) The NMDA antagonist MK-801 disrupts reconsolidation of a cocaine-associated memory for conditioned place preference but not for self-administration in rats. Learn Mem 15:857-865.

Cador M, Robbins TW, Everitt BJ (1989) Involvement of the amygdala in stimulus-reward associations: interaction with the ventral striatum. Neuroscience 30:77-86.

Cahill L, McGaugh JL, Weinberger NM (2001) The neurobiology of learning and memory: some reminders to remember. Trends Neurosci 24:578581.

Conklin CA, Tiffany ST (2002) Applying extinction research and theory to cue-exposure addiction treatments. Addiction 97:155-167.

Crombag HS, Shaham Y (2002) Renewal of drug seeking by contextual cues after prolonged extinction in rats. Behav Neurosci 116:169-173.

Debiec J, LeDoux JE (2006) Noradrenergic signaling in the amygdala contributes to the reconsolidation of fear memory: treatment implications for PTSD. Ann N Y Acad Sci 1071:521-524.

Dudai Y (2006) Reconsolidation: the advantage of being refocused. Curr Opin Neurobiol 16:174-178.

Dudai Y, Eisenberg M (2004) Rites of passage of the engram: reconsolidation and the lingering consolidation hypothesis. Neuron 44:93-100.

Eisenberg M, Dudai Y (2004) Reconsolidation of fresh, remote, and extinguished fear memory in medaka: old fears don't die. Eur J Neurosci 20:3397-3403.

Everitt BJ, Cador M, Robbins TW (1989) Interactions between the amygdala and ventral striatum in stimulus-reward associations: studies using a second-order schedule of sexual reinforcement. Neuroscience 30:63-75.

Feltenstein MW, See RE (2007) NMDA receptor blockade in the basolateral amygdala disrupts consolidation of stimulus-reward memory and extinction learning during reinstatement of cocaine-seeking in an animal model of relapse. Neurobiol Learn Mem 88:435-444.

Feltenstein MW, See RE (2008) The neurocircuitry of addiction: an overview. Br J Pharmacol 154:261-274.

Fuchs RA, Feltenstein MW, See RE (2006) The role of the basolateral amygdala in stimulus-reward memory and extinction memory consolidation and in subsequent conditioned cued reinstatement of cocaine seeking. Eur J Neurosci 23:2809-2813.

Goosens KA, Holt W, Maren S (2000) A role for amygdaloid PKA and PKC in the acquisition of long-term conditional fear memories in rats. Behav Brain Res 114:145-152.

Grimm JW, See RE (2000) Dissociation of primary and secondary rewardrelevant limbic nuclei in an animal model of relapse. Neuropsychopharmacology 22:473-479.

Hellemans KG, Everitt BJ, Lee JL (2006) Disrupting reconsolidation of conditioned withdrawal memories in the basolateral amygdala reduces suppression of heroin seeking in rats. 26:12694-12699.

Huang YY, Kandel ER (1998) Postsynaptic induction and PKA-dependent expression of LTP in the lateral amygdala. Neuron 21:169-178.

Huang YY, Martin KC, Kandel ER (2000) Both protein kinase A and mitogenactivated protein kinase are required in the amygdala for the macromolecular synthesis-dependent late phase of long-term potentiation. J Neurosci 20:6317-6325.

Jentsch JD, Taylor JR (1999) Impulsivity resulting from frontostriatal dysfunction in drug abuse: implications for the control of behavior by reward-related stimuli. Psychopharmacology 146:373-390.

Jentsch JD, Olausson P, Nestler EJ, Taylor JR (2002) Stimulation of protein kinase A activity in the rat amygdala enhances reward-related learning. Biol Psychiatry 52:111-118.

Kantak KM, Black Y, Valencia E, Green-Jordan K, Eichenbaum HB (2002) Dissociable effects of lidocaine inactivation of the rostral and caudal basolateral amygdala on the maintenance and reinstatement of cocaineseeking behavior in rats. J Neurosci 22:1126-1136.

Kelley JB, Anderson KL, Itzhak Y (2007) Long-term memory of cocaineassociated context: disruption and reinstatement. Neuroreport 18:777-780.

Lattal KM, Abel T (2004) Behavioral impairments caused by injections of the protein synthesis inhibitor anisomycin after contextual retrieval reverse with time. Proc Natl Acad Sci U S A 101:4667-4672. 
Lee JL (2008) Memory reconsolidation mediates the strengthening of memories by additional learning. Nat Neurosci 11:1264-1266.

Lee JL, Di Ciano P, Thomas KL, Everitt BJ (2005) Disrupting reconsolidation of drug memories reduces cocaine-seeking behavior. Neuron 47:795-801.

Lee JL, Milton AL, Everitt BJ (2006) Cue-induced cocaine seeking and relapse are reduced by disruption of drug memory reconsolidation. J Neurosci 26:5881-5887.

Lee JL, Gardner RJ, Butler VJ, Everitt BJ (2009) D-cycloserine potentiates the reconsolidation of cocaine-associated memories. Learn Mem $16: 82-85$.

Mactutus CF, Riccio DC, Ferek JM (1979) Retrograde amnesia for old (reactivated) memory: some anomalous characteristics. Science 204: $1319-1320$

McCleery JM, Harvey AG (2004) Integration of psychological and biological approaches to trauma memory: implications for pharmacological prevention of PTSD. J Trauma Stress 17:485-496.

Miller CA, Marshall JF (2005) Molecular substrates for retrieval and reconsolidation of cocaine-associated contextual memory. Neuron 47:873-884.

Miller RR, Matzel LD (2006) Retrieval failure versus memory loss in experimental amnesia: definitions and processes. Learn Mem 13:491-497.

Milton AL, Lee JL, Butler VJ, Gardner R, Everitt BJ (2008) Intra-amygdala and systemic antagonism of NMDA receptors prevents the reconsolidation of drug-associated memory and impairs subsequently both novel and previously acquired drug-seeking behaviors. J Neurosci 28:8230-8237.

Nader K, Hardt O (2009) A single standard for memory: the case for reconsolidation. Nat Rev Neurosci 10:224-234.

O’Brien CP, Childress AR, McLellan T, Ehrman R (1990) Integrating systemic cue exposure with standard treatment in recovering drug dependent patients. Addict Behav 15:355-365.

Paxinos G, Watson C (2005) The rat brain in stereotaxic coordinates, Ed 5. Boston: Elsevier Academic.

Power AE, Berlau DJ, McGaugh JL, Steward O (2006) Anisomycin infused into the hippocampus fails to block "reconsolidation" but impairs extinction: the role of re-exposure duration. Learn Mem 13:27-34.

Rammes G, Steckler T, Kresse A, Schütz G, Zieglgänsberger W, Lutz B (2000) Synaptic plasticity in the basolateral amygdala in transgenic mice expressing dominant-negative cAMP response element-binding protein (CREB) in forebrain. Eur J Neurosci 12:2534-2546.

Riccio DC, Millin PM, Bogart AR (2006) Reconsolidation: a brief history, a retrieval view, and some recent issues. Learn Mem 13:536-544.

Robbins TW, Ersche KD, Everitt BJ (2008) Drug addiction and the memory systems of the brain. Ann N Y Acad Sci 1141:1-21.

Roullet P, Sara S (1998) Consolidation of memory after its reactivation: involvement of beta noradrenergic receptors in the late phase. Neural Plast 6:63-68.

Schafe GE, LeDoux JE (2000) Memory consolidation of auditory Pavlovian fear conditioning requires protein synthesis and protein kinase $\mathrm{A}$ in the amygdala. J Neurosci 20:RC96(1-5).

Squire LR (2006) Lost forever or temporarily misplaced? The long debate about the nature of memory impairment. Learn Mem 13:522-529.

Taylor JR, Olausson P, Quinn JJ, Torregrossa MM (2009) Targeting extinction and reconsolidation mechanisms to combat the impact of drug cues on addiction. Neuropharmacology 56:186-195.

Tronson NC, Taylor JR (2007) Molecular mechanisms of memory reconsolidation. Nat Rev Neurosci 8:262-275.

Tronson NC, Wiseman SL, Olausson P, Taylor JR (2006) Bidirectional behavioral plasticity of memory reconsolidation depends on amygdalar protein kinase A. Nat Neurosci 9:167-169.

Volkow ND, Wang GJ, Telang F, Fowler JS, Logan J, Childress AR, Jayne M, Ma Y, Wong C (2008) Dopamine increases in striatum do not elicit craving in cocaine abusers unless they are coupled with cocaine cues. Neuroimage 39:1266-1273.

Weiss F, Martin-Fardon R, Ciccocioppo R, Kerr TM, Smith DL, Ben-Shahar O (2001) Enduring resistance to extinction of cocaine-seeking behavior induced by drug-related cues. Neuropsychopharmacology 25:361-372. 